QATALOQUE LIBRARK MAR I IRRT
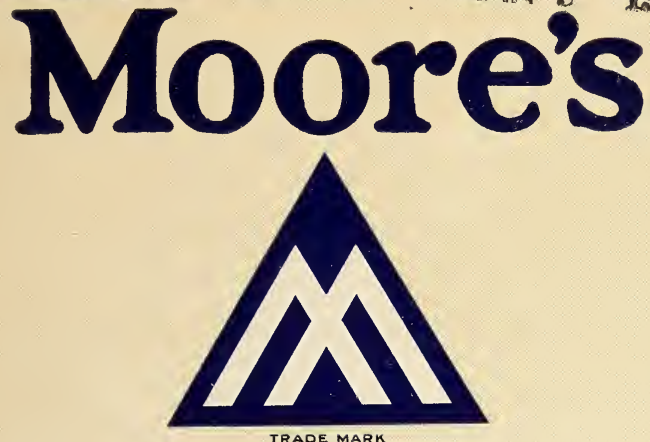

TRADE MARK
REG.U.S.PAT.OFF.

Interior

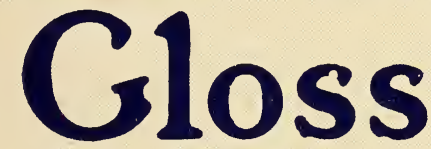

For Walls

and Woodwork

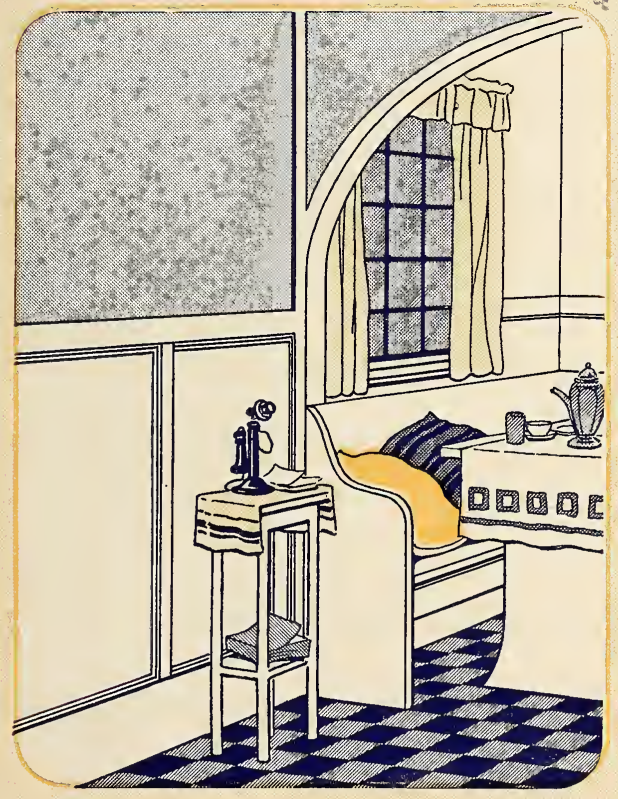

\title{
MANUFACTURED BY
} Benjamin Moore $\mathcal{E}$ Co.

NEW YORK CHICAGO CLEVELAND

ST.LOUIS CARTERET TORONTO 


\section{Moore's}

\section{Interior Gloss}

For Walls and Woodwork

Moore's Interior Gloss is an enamellike paint made especially for walls and woodwork in kitchens, bathrooms, hallways, stores and any interior surface where a high gloss, durable finish is desired. It can be applied on plaster, cement, wood, wall board or metal surfaces with satisfactory and pleasing results when directions are followed. This paint retains its color for a great length of time and it is not affected by fumes or moisture.

Moore's Interior Gloss is washable.

Realizing the importance of color in the home, great thought has been given the colors in which this paint is manufactured. They are bright and cheerful so as to lend that atmosphere of coziness and cheerfulness that is so much desired.

Moore's Interior Gloss spreads without difficulty under the brush-it has great covering properties and flows out to a smooth enamel-like finish. 
IVORY

LIGHT BUFF

BUFF

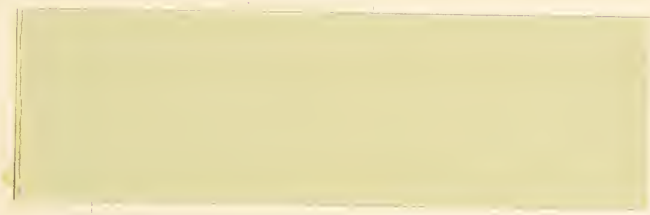

LIGHT GRAY

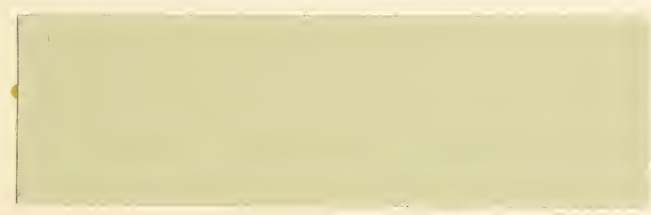

GRAY TINT

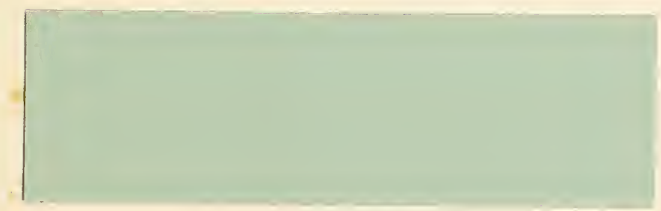

LIGHT BLUE

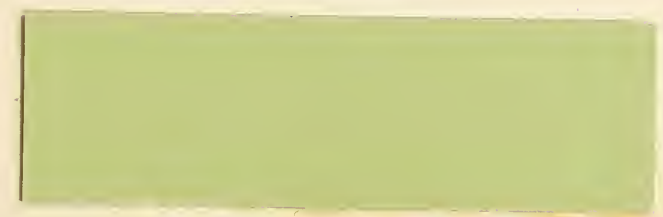

PEA GREEN

\section{ALSO MADE IN WHITE} DSI 


\section{Moore's}

Interior

\section{Gloss}

\section{Directions For Use}

Shake the package well before opening. Then stir to a uniform consistency. Make certain that the surface to be painted is clean, dry and free from grease. Dark painted surfaces that are to be repainted with light colors should first receive one or two coats of flat paint similar in shade to the Moore's Interior Gloss used. This also applies to new work.

Add no thinners of any kind unless the weather is cold or the paint has thickened on account of evaporation. Then add pure turpentine only in small quantity.

Use a fine bristle brush except on large wall surfaces where a flat paint brush may be used. Do not rub or brush out the paint too much but flow on freely and lay off evenly. 